\title{
Long-term Clinical and Angiographic Follow-up of the New Non-Polymeric Paclitaxel-Eluting Stent for the Treatment of De Novo Coronary Lesions: Outcomes of the PAX-B Study
}

\author{
Erlon O. de Abreu-Silva ${ }^{1}$, Ricardo A. Costa ${ }^{2}$, Andrea Abizaid ${ }^{3}$, Angelo Ramondo ${ }^{4}$, Philippe Brenot ${ }^{5}$, \\ Hakim Benamer ${ }^{6}$, Alessandro Desideri ${ }^{7}$, Jacques Berland ${ }^{8}$, Breno O. Almeida ${ }^{9}$, Franck Digne ${ }^{10}$, \\ Marco A. Perin ${ }^{11}$, Juliana P. de Castro' ${ }^{12}$, J. Ribamar Costa Jr. ${ }^{13}$, Rodolfo Staico ${ }^{13}$, Luiz F. Tanajura ${ }^{14}$, \\ Alexandre Abizaid ${ }^{15}$, on behalf of the PAX-B study Investigators
}

\begin{abstract}
Background: Compared with the $\operatorname{Taxus}^{\circledR}$ stent, the nonpolymeric paclitaxel-eluting Amazonia ${ }^{\circledR}$ PAX stent shows no differences in the occurrence of coronary restenosis or clinical events after four months of follow-up. However, the performance of the Amazonia ${ }^{\circledR}$ PAX stent in more complex cases and with longer angiographic follow-up has not been demonstrated. Methods: The PAX-B study was a prospective, non-randomised, multicentre study assessing the long-term follow-up of patients treated with the Amazonia ${ }^{\circledR}$ PAX stent. The primary outcome was late in-stent lumen loss. Results: The study included 103 patients with a mean age of $61.3 \pm 11.4$ years; $26.2 \%$ were diabetics, $24.3 \%$ had acute coronary syndromes, and $71.6 \%$ had type B2/C lesions. Multiple stents were implanted in $4.7 \%$ of the patients, and angiographic success was achieved in $100 \%$ of the cases. During hospitalisation, the periprocedural acute myocardial infarction rate was $3.9 \%$, and one of these events led to target-lesion revascularisation (TLR). At the nine-month angiographic follow-up, the median late in-stent lumen loss was $0.91[0.50 ; 1.21] \mathrm{mm}$. The cumulative rates of major adverse cardiac events at the six-month, nine-month, and 12 -month follow-ups were $7.8 \%, 18.5 \%$, and $21.3 \%$,
\end{abstract}

\section{RESUMO}

\section{Seguimento Angiográfico e Clínico Tardio do Novo Stent Farmacológico Não Polimérico Liberador de Paclitaxel para o Tratamento de Lesões Coronárias De Novo: Resultados do Estudo PAX-B}

Introdução: O stent farmacológico eluidor de paclitaxel, não polimérico, Amazonia ${ }^{\circledR}$ PAX não mostrou diferença na reestenose coronária ou eventos clínicos aos 4 meses de evolução quando comparado com o stent Taxus ${ }^{\circledR}$. Entretanto, o desempenho do stent Amazonia ${ }^{\circledR}$ PAX em cenários de maior complexidade e com seguimento angiográfico mais longo ainda não foi demonstrado. Métodos: O Estudo PAX-B foi um estudo prospectivo, não randomizado, multicêntrico, que avaliou os resultados tardios de pacientes tratados com o stent Amazonia ${ }^{\circledR}$ PAX. O desfecho primário foi a perda tardia do lúmen intrastent. Resultados: Foram incluídos 103 pacientes com média de idade de $61,3 \pm 11,4$ anos, $26,2 \%$ eram diabéticos, 24,3\% apresentaram-se com síndrome coronária aguda e $71,6 \%$ tinham lesões tipo B2/C. Implante de múltiplos stents ocorreu em $4,7 \%$ dos casos e o sucesso angiográfico foi de $100 \%$. Na fase hospitalar, a taxa de infarto agudo do miocárdio periprocedimento foi de $3,9 \%$, e um desses eventos
1 Physician; Interventional cardiologist. Research Fellow, Cardiovascular Research Center. São Paulo, SP, Brazil.

${ }^{2} \mathrm{PhD}$ Physician; Interventional cardiologist at the Invasive Cardiology Service of the Instituto Dante Pazzanese de Cardiologia. São Paulo, SP, Brazil. ${ }^{3}$ PhD Physician; Cardiologist at the Instituto Dante Pazzanese de Cardiologia. São Paulo, SP, Brazil.

${ }^{4}$ Physician. Director of the Cardiology Service at the Azienda Ospedaliera di Padova. Pádova, Italy.

${ }^{5}$ Physician of the Department of Radiology, Cardiovascular Surgery and Cardiology of the Centre Chirurgical Marie Lannelongue. Le PlessisRobinson, France.

${ }^{6}$ Physician at the Service of Interventional Cardiology of Hôpital Européen de Paris La Roseraie. Aubervilliers, France.

$7 \mathrm{PhD}$; Director of the Fondazione per la Ricerca Cardiovascolare do Ospedale San Giacomo. Castelfranco Veneto, Italy.

${ }^{8}$ Physician at the Cardiology Service of Clinique Saint Hilaire. Rouen, France.

${ }^{9}$ Graduate Student at the Instituto Dante Pazzanese de Cardiologia. Physician; Interventional cardiologist and Coordinator of the Interventional Cardiology at Hospital Santa Marcelina. São Paulo, SP, Brazil.

\begin{abstract}
10 "Physician in charge" of the Centre Cardiologique du Nord Saint Denis. Paris, France.

${ }^{11} \mathrm{PhD}$; Head of the Sector of the Cardiovascular Intervention of Hospital Israelita Albert Einstein. São Paulo, SP, Brazil.

12 PhD; Clinical Research Manager of the Cardiovascular Research Center. São Paulo, SP, Brazil.

${ }^{13}$ PhD Physician; Interventional cardiologist at the Invasive Cardiology Service of Instituto Dante Pazzanese de Cardiologia. São Paulo, SP, Brazil. ${ }^{14} \mathrm{PhD}$; Head of the Medical Section of Coronary Angioplasty of the Instituto Dante Pazzanese de Cardiologia. São Paulo, SP, Brazil.

15 Tenured Professor. Director of the Invasive Cardiology Service of the Instituto Dante Pazzanese de Cardiologia. São Paulo, SP, Brazil.
\end{abstract}

Correspondence to: Ricardo A. Costa. Rua Dr. Astolfo Araújo, 521 - Vila Mariana - São Paulo, SP, Brazil - CEP 04012-070

E-mail: rcosta@dantepazzanese.org.br

Received on: 4/2/2012 • Accepted on: 6/12/2012 
respectively, mostly due to TLR. There were no deaths or stent thromboses at 12 months. Conclusions: The Amazonia ${ }^{\circledR}$ PAX stent showed excellent immediate results and a good safety profile. However, angiographic recurrence rates were relatively high because of the low efficacy of neointimal hyperplasia inhibition.

DESCRIPTORS: Drug-eluting stents. Paclitaxel. Coronary disease. Coronary thrombosis.

4 nitially, first-generation drug-eluting stents (DES) with durable polymers were shown to be effective in the treatment of selected coronary lesions due to the significant reduction in neointimal hyperplasia formation, restenosis and, consequently, the need to perform target lesion revascularisation (TLR), when compared to baremetal stents (BMS). ${ }^{1-3}$ However, despite the remarkable effectiveness of these devices in different scenarios, ${ }^{4}$ concerns related to their safety profile and long-term safety ${ }^{5}$ have led to the development of new technologies, aiming to optimise results. ${ }^{6-11}$

Specifically, late stent thrombosis post-DES has been considered a rare and multifactorial phenomenon, ${ }^{12,13}$ involving delayed strut endothelialisation and healing of the treated segment. ${ }^{14,15}$ Previous pathological studies demonstrated that the presence of durable polymer debris was associated with inflammation and eosinophil infiltration in the artery wall and is thus a potentially thrombogenic factor. ${ }^{15,16}$ Therefore, non-polymeric DES were developed as an alternative to earlier generation DES, which used polymers as a drug carrier system. $6,17,18$

The Amazonia PAX ${ }^{\circledR}$ device (Minvasys SAS - Gennevillieres, France) is a DES that incorporates a low profile platform and an antiproliferative agent, paclitaxel, which is applied directly to the surface of the device without the use of a polymer. Recently published data from the initial study on the device (vs. Taxus ${ }^{\circledR}$ Liberté DES, Boston Scientific - Natick, MA, USA) showed no significant differences in the occurrence of angiographic restenosis at four months or clinical events up to 12 months in a small sample of patients from a single-centre study. ${ }^{19}$ However, the performance of the Amazonia $\mathrm{PAX}^{\circledR}$ stent in more complex scenarios, with more patients and over longer angiographic follow-up has not been determined. The present study aimed to report the nine-month angiographic follow-up and the long-term clinical outcomes of patients treated with the Amazonia $\mathrm{PAX}^{\circledR}$ stent in a prospective, multicentre study. levou à revascularização da lesão-alvo (RLA). No seguimento angiográfico de 9 meses, a mediana da perda tardia do lúmen intrastent foi de $0,91[0,50 ; 1,21] \mathrm{mm}$. As taxas cumulativas de eventos cardíacos adversos maiores nos seguimentos de 6 meses, 9 meses e 12 meses foram, respectivamente, de 7,8\%, $18,5 \%$ e $21,3 \%$, principalmente em decorrência de RLA Não se observou morte ou trombose de stent em 12 meses. Conclusões: $O$ stent Amazonia ${ }^{\circledR}$ PAX demonstrou excelentes resultados imediatos e alto perfil de segurança. Entretanto, as taxas de recorrência angiográfica foram relativamente altas, em razão da pouca eficácia na inibição da formação de hiperplasia neointimal.

DESCRITORES: Stents farmacológicos. Paclitaxel. Doença das coronárias. Trombose coronária.

\section{METHODS}

\section{Study protocol and population}

The PAX-B study was a prospective, nonrandomised, multicentre, international study that aimed to evaluate the long-term clinical and angiographic outcomes of patients with obstructive coronary artery disease treated with the Amazonia $P A X^{\circledR}$ stent in nine clinical centres, of which seven were located in Europe and two were located in Brazil. The study population included patients aged $\geq 18$ years, with stable or unstable angina and/or a stress test positive for ischaemia. The angiographic inclusion criteria were the presence of a de novo coronary lesion with stenosis of $\geq 50 \%$ and a length of $\leq 20 \mathrm{~mm}$ by visual analysis, located in a natural coronary artery, with a reference diameter between $2.5 \mathrm{~mm}$ and $3.5 \mathrm{~mm}$, as well as a favourable anatomy for percutaneous coronary intervention with stent implantation. The main exclusion criteria were acute myocardial infarction within $<72$ hours of the index procedure; renal failure with basal serum creatinine $\geq 2 \mathrm{mg} /$ $\mathrm{dL}$; previous percutaneous coronary intervention of the target lesion; previous coronary intervention of the target vessel within nine months of the index procedure; cardiogenic shock; cerebrovascular accident; lesions located in a coronary bifurcation, left main coronary artery or saphenous vein bypass graft; calcification and/or significant tortuosity; total occlusion; left ventricular ejection fraction of $<30 \%$; and hypersensitivity or contraindication to aspirin and/or thienopyridine (clopidogrel). ${ }^{19}$ According to the protocol, treatment of up to two lesions per patient was permitted, as long as a single lesion was treated per target vessel.

The study was in conducted accordance with the Declaration of Helsinki, was approved by the Ethics Committee of the participating clinical centres, and complied with the mandatory regulations and requirements of the Comissão Nacional de Ética em Pesquisa (Brazilian National Research Ethics Commission, CONEP). Furthermore, all participating patients signed an informed consent prior to study inclusion. 


\section{Device description}

The design, profile, and characteristics of the Amazonia $P A X^{\circledR}$ stent have been detailed elsewhere. ${ }^{19}$ In summary, this device incorporates a low-profile metallic cobalt-chromium platform, with a thickness of $73 \mu \mathrm{m}$, an open-cell modular design, and an antiproliferative agent, paclitaxel, which is applied directly to the abluminal surface of the stent struts by a microdrop spray crystallisation process. This procedure only adds $5 \mu \mathrm{m}$ to strut thickness and aims to ensure the integrity of the drug and a controlled release profile.

\section{Procedure}

The percutaneous procedures were performed according to current guidelines, ${ }^{20}$ and the final procedure was left to the surgeon's discretion. Direct stent implantation was allowed. The implantation of an additional stent in the target lesion was allowed if dissection and/or the need for complete coverage of the lesion and the treatment of multiple lesions (maximum of two in distinct target vessels) was permitted according to the protocol. Notably, only patients treated exclusively with Amazonia $P A X^{\circledR}$ stents were considered for the final analysis of the PAX-B study. Amazonia PAX ${ }^{\circledR}$ stents with diameters of $2.5 \mathrm{~mm}, 3 \mathrm{~mm}$, and $3.5 \mathrm{~mm}$, and extensions of $8 \mathrm{~mm}, 12 \mathrm{~mm}, 16 \mathrm{~mm}, 20 \mathrm{~mm}$, and $24 \mathrm{~mm}$ were available for the study.

Dual antiplatelet therapy consisted of the administration of aspirin (100-325 mg/day) and thienopyridine (75 mg/day of clopidogrel). In case of failure or intolerance, the administration of $250 \mathrm{mg}$ of ticlopidine two times daily was allowed. The administration of clopidogrel was started at least 24 hours before the procedure, and a loading dose of $300 \mathrm{mg}$ (or $500 \mathrm{mg}$ of ticlopidine) was recommended. After the procedure, aspirin therapy was maintained indefinitely, and thienopyridine therapy was maintained for at least 12 months, as currently recommended. ${ }^{20}$ Regarding antithrombin therapy during the procedure, unfractionated heparin (UFH) was administered intravenously at a dose of 70-100 U/kg to maintain an activated coagulation time of $>250$ seconds (or > 200 seconds in case of glycoprotein Ilb/IIla inhibitor use, which was administered at the surgeon's discretion).

Regarding additional tests, a 12-lead electrocardiogram was obtained before, immediately after, and 24 hours after the procedure. Laboratory tests for cardiac enzymes (creatine phosphokinase and creatine kinase MB-fraction) were conducted pre-procedure $(<72$ hours) and every six to eight hours during the first 24 hours after the procedure or until hospital discharge.

\section{Outcomes and definitions}

The primary study endpoint was late lumen loss in the in-stent segment, as assessed by a quantitative coronary angiography analysis at the nine-month follow-up. Secondary endpoints were target vessel failure, TLR and target-vessel revascularisation (TVR) at the nine-month follow-up, immediate success (of the device, lesion, and procedure), major adverse cardiac events (MACE), and binary restenosis assessed by quantitative coronary angiography at the nine-month follow-up. All deaths were considered to be cardiac unless a noncardiac cause could be clearly established by clinical evaluation or anatomopathological studies. Target vessel failure was defined as the composite endpoint of TVR, myocardial infarction, and cardiac death. MACE were defined by the composite endpoint of death, myocardial infarction, and target-lesion revascularisation (percutaneous or surgical). Stent thrombosis was defined according to the criteria of the Academic Research Consortium. ${ }^{21}$ Device success was defined as the successful delivery and implantation of the study stent at the lesion site. The lesion success (angiographic) was defined by achieving a stenosis diameter (SD) of $<50 \%$ in the target lesion after the procedure. Procedural success was defined as lesion success without the occurrence of MACE during the index hospitalisation.

\section{Angiographic analysis}

The acquisition of angiographic images occurred after the intracoronary administration of nitrate (100$200 \mu \mathrm{g}$ ) and included two orthogonal projections (> 30 degrees), which aimed to optimise the visualisation of the target lesion. The qualitative and quantitative angiographic analyses were performed serially pre- and post-procedure and at the nine-month follow-up, and were independently analysed by the Angiographic Analysis Laboratory of the Cardiovascular Research Centre (São Paulo, SP, Brazil). Overall, the qualitative analysis followed previously established definitions, including characteristics of the vessel, lesion morphology, and coronary flow. ${ }^{22}$ The analyses of quantitative coronary angiography were performed off-line by surgeons who were experienced with the methods and blinded to procedural data, using a computerised quantitative analysis system with semi-automatic detection for luminal borders, which has been validated, is commercially available (QAngio ${ }^{\circledR} \mathrm{XA}$, version 7.2, Medis - Leiden, the Netherlands), and incorporates a tool to perform the segmental analysis. Lesion extension was delimited by the distance between points immediately before and after the target-stenosis considered free of atheromatous processes, i.e., the transition between the stenotic segment and the normal references (5-10 mm). The minimal lumen diameter (MLD) and the reference vessel diameter (RVD) were used to calculate SD using the formula: SD $(\%)=[1-($ MLD/RVD) $] \times 100$. Immediate gain was defined as the difference in MLD pre- and post-procedure (MLD post-procedure minus pre-procedural MLD). Late lumen loss was defined as the difference in MLD after the procedure and at the 
long-term follow-up (MLD post-procedure minus MLD at the nine-month follow-up). Binary restenosis was defined as the presence of $\mathrm{SD} \geq 50 \%$ in the treated segment at the long-term follow-up and was classified as focal $(<10 \mathrm{~mm})$ or diffuse $(\geq 10 \mathrm{~mm})$. The restenoses were also classified according to Mehran. ${ }^{23}$ Quantitative variables were reported in the in-stent and intra-segment segments, which incorporates the in-stent segment and $5 \mathrm{~mm}$ of the borders. ${ }^{6}$

\section{Clinical follow-up and database}

Clinical follow-up was planned at one month, six months, nine months, and 12 months after the procedure and annually for up to five years. The follow-up consisted of medical consultations or telephone contact, performed in accordance with a pre-defined protocol. At the nine-month follow-up, an angiographic study was mandatory. The electronic data capture system that was used was based on an Oracle platform (Redwood Shores, CA, USA), with restricted access through personal passwords. In $100 \%$ of the cases, the data were verified to correct any discrepancies or inconsistent information through remote monitoring. Physical monitoring (in person) was performed in a sample of $15 \%$ of the cases, selected at random. For both remote and physical monitoring, the procedures were the responsibility of the study's data coordinating centre. All adverse events were verified directly with the source documentation and were subsequently adjudicated by an independent clinical events committee consisting of three professionals experienced in clinical and invasive cardiology. For the current analysis, the results of the procedure, the angiographic restudy at nine months, and the clinical follow-up up to 12 months are reported.

\section{Statistical analysis}

Categorical variables are shown as absolute numbers and frequencies. Quantitative variables are shown as mean and standard deviation $( \pm \mathrm{SD})$ or median and interquartile range $[25 \% ; 75 \%]$.

\section{RESULTS}

A total of 103 patients were enrolled between December, 2008 and November, 2009. The baseline characteristics are shown in Table 1. Overall, the mean age was $61.3 \pm 11.4$ years, $26.2 \%$ were diabetics, and $41.7 \%$ had a previous myocardial infarction. Regarding the clinical presentation, approximately half of the patients had stable angina.

Angiographic data are shown in Table 2. In total, 127 lesions were included (1.24 \pm 0.43 lesions per patient) and the anterior descending artery was the target vessel most often treated (39.4\%). Additionally, high-complexity lesions (type B2/C) were found in most cases $(71.6 \%)$. During the procedure,
TABLE 1 Baseline Clinical Characteristics

\begin{tabular}{lc}
\hline Variable & $\begin{array}{c}\mathbf{n}=\mathbf{1 0 3} \\
\text { patients }\end{array}$ \\
\hline Mean age, years & $61.3 \pm 11.4$ \\
Female gender, n (\%) & $24(23,3)$ \\
Diabetes mellitus, n (\%) & $27(26.2)$ \\
Insulin in use & $5(4.8)$ \\
Systemic arterial hypertension, n (\%) & $74(71.8)$ \\
Dyslipidemia, n (\%) & $64(62.1)$ \\
Smoking, n (\%) & $23(22.3)$ \\
Previous AMI, n (\%) & $43(41.7)$ \\
Previous PCl, n (\%) & $20(19.4)$ \\
Previous CABG, n (\%) & 0 \\
Clinical presentation, n (\%) & \\
Silent ischemia & $29(28.1)$ \\
Stable angina & $49(47.6)$ \\
Unstable angina & $25(24.3)$ \\
\hline
\end{tabular}

$\mathrm{AMI}=$ acute myocardial infarction; $\mathrm{PCl}=$ percutaneous coronary intervention; CABG = coronary artery bypass graft.

radial access was used in $46.6 \%$ of the cases, and a second stent in the target lesion was implanted in $4.7 \%$ of the cases (Table 3 ). At the end of the $\mathrm{PCI}$, both angiographic success and device success were achieved in $100 \%$ of the cases.

Table 4 shows the pre- and post-procedure results of the quantitative coronary angiography analysis. At the nine-month angiographic follow-up $(92.1 \%$ of the lesions), the medians of the late intra-segment and instent lumen loss were $0.64[0.32 ; 0.92] \mathrm{mm}$ and 0.91 $[0.50 ; 1.21] \mathrm{mm}$, respectively (Table 5 ). The rate of restenosis was $19.7 \%$, and most recurrent cases were of focal in-stent type (Table 6).

Regarding clinical events while in the hospital, four patients $(3.9 \%)$ had periprocedural myocardial infarctions (all without Q-wave), and one of these events led to TLR. In this case, the patient returned to the haemodynamics laboratory on the same day of the index procedure since he exhibited ischaemic symptoms after the procedure. At the angiographic assessment, a dissection was observed at the border of the previously implanted stent, which was treated with an additional stent implantation, overlapping with the struts of the other stent. Between hospital discharge and 30 days after the procedure, there was one instance of new myocardial infarction (non-Q). Figure 1 shows the cumulative rates of adverse events after hospital discharge up to the 12-month follow-up 
TABLE 2

Angiographic Data

\begin{tabular}{lc}
\hline Variable & $\begin{array}{c}\mathbf{n}=\mathbf{1 2 7} \\
\text { lesions }\end{array}$ \\
\hline Target-vessel, n (\%) & $50(39.4)$ \\
ADA & $44(34.7)$ \\
Cx & $33(26)$ \\
RCA & \\
Location (segment), n (\%) & $1(0.8)$ \\
Ostial & $47(37)$ \\
Proximal & $64(50.4)$ \\
Medium & $15(11.8)$ \\
Distal & \\
Type of lesion (ACC/AHA), n (\%) & $13(10.2)$ \\
A & $23(18.1)$ \\
B1 & $84(66.1)$ \\
B2 & $7(5.5)$ \\
C & \\
\hline ACC = American College of Cardiology; AHA = American \\
Heart Association; RCA = right coronary artery; Cx $=$ circumflex \\
artery; ADA = anterior descending artery. \\
\hline
\end{tabular}

TABLE 3

Procedure

\begin{tabular}{lc}
\hline Variable & $\begin{array}{c}\mathbf{n}=\mathbf{1 0 3} \text { patients } \\
\mathbf{( 1 2 7} \text { lesions) }\end{array}$ \\
\hline Radial access, $\mathrm{n}(\%)$ & $48 / 103(46.6)$ \\
Pre-dilation, $\mathrm{n}(\%)$ & $54 / 127(42.5)$ \\
Nominal balloon extension, mm & $13.9 \pm 3.2$ \\
Nominal balloon diameter, mm & $2.68 \pm 0.88$ \\
Balloon insufflation pressure, atm & $10.6 \pm 2.9$ \\
Implanted study stent, $\mathrm{n}(\%)$ & $127 / 127(100)$ \\
Nominal stent extension, mm & $16.9 \pm 3.9$ \\
Nominal stent diameter, mm & $3.02 \pm 0.37$ \\
Stent release pressure, atm & $13.5 \pm 3.5$ \\
Additional implanted stent, $\mathrm{n}(\%)$ & $6 / 127(4.7)$ \\
Post-dilation, $\mathrm{n}$ (\%) & $73 / 127(57.5)$ \\
Nominal balloon extension, mm & $11.5 \pm 2.6$ \\
Nominal balloon diameter, mm & $3.21 \pm 0.41$ \\
Balloon insufflation pressure, atm & $16.9 \pm 3.8$ \\
Final TIMl flow grade 3, $\mathrm{n}(\%)$ & $127 / 127(100)$ \\
\hline TIMl = thrombolysis in myocardial infarction. \\
\hline
\end{tabular}

TABLE 4

Pre- and Post-procedural Quantitative Angiography

\begin{tabular}{lc}
\hline Variable & $n=127$ \\
& lesions \\
\hline
\end{tabular}

\begin{tabular}{lc} 
Pre-procedure & \\
Lesion extension, mm & $2.1[9.9 ; 15.8]$ \\
RVD, mm & $2.92[2.64 ; 3.21]$ \\
MLD, mm & $0.70[0.43 ; 1.00]$ \\
SD, \% & $74.8[64.8 ; 86.0]$ \\
Post-procedure & \\
RVD, mm & $2.95[2.70 ; 3.30]$ \\
Intra-segment & \\
MLD, mm & $2.46[2.22 ; 2.77]$ \\
SD, \% & $15[10.3 ; 21.1]$ \\
Immediate gain, mm & $1.74[1.40 ; 2.06]$ \\
Intrastent & \\
MLD, mm & $2.79[2.53 ; 3.11]$ \\
SD, \% & $5.7[3.6 ; 8.5]$ \\
Immediate gain, mm & $2[1.72 ; 2.40]$ \\
Baloon:artery ratio & $1.10[1.06 ; 1.16]$ \\
\hline $\begin{array}{l}\text { MLD = minimal lumen diameter; RVD } \\
\text { diameter; SD = stenosis diameter. }\end{array}$ & \\
\hline
\end{tabular}

TABLE 5

Angiographic follow-up at nine months

\begin{tabular}{lc}
\hline Variable & $\mathbf{n}=\mathbf{1 1 7}$ lesions \\
\hline RVD, mm & $2.81[2.41 ; 3.07]$ \\
Intra-segment & \\
MLD, mm & $1.84[1.40 ; 2.25]$ \\
SD, \% & $31.7[21.5 ; 44.7]$ \\
Late lumen loss, mm & $0.64[0.32 ; 0.92]$ \\
Intrastent & \\
MLD, mm & $1.94[1.41 ; 2.30]$ \\
SD, \% & $27.3[16.4 ; 41.8]$ \\
Late lumen loss, mm & $0.91[0.50 ; 1.21]$ \\
\hline MLD = minimal lumen diameter; RVD $=$ reference vessel \\
diameter; SD = stenosis diameter.
\end{tabular}

(100\% of patients). In general, rates of target vessel failure $(22.3 \%)$ and MACE $(22.3 \%)$ after one year were directly related to the rates of TLR and TVR. There were no deaths from stent thrombosis or any other cause during follow-up. 
TABLE 6

Binary restenosis

\begin{tabular}{lc}
\hline $\begin{array}{l}\text { Angiographic follow-up at } \\
\text { nine months }\end{array}$ & $\begin{array}{c}\mathbf{n}=\mathbf{1 1 7} \\
\text { lesions }\end{array}$ \\
\hline Total, $\mathrm{n}(\%)$ & $23(19.7)$ \\
${\text { Mehran's classification, }{ }^{23} \mathrm{n}}^{\prime}$ & \\
Type 1A & 0 \\
Type 1B & 0 \\
Type 1C & 18 \\
Type 1D & 0 \\
Type 2 & 2 \\
Type 3 & 0 \\
Type 4 & 3 \\
\hline
\end{tabular}

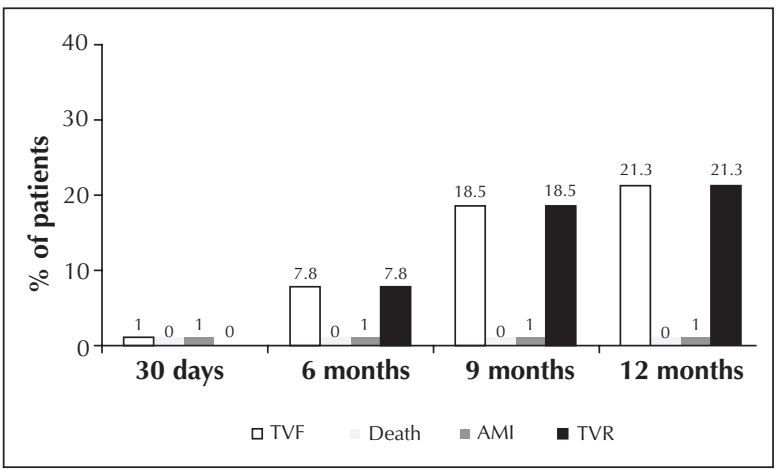

Figure 1 - Cumulative adverse events after hospital discharge up to 12 months of clinical follow-up $(n=103)$. TVF = target vessel failure, $\mathrm{AMI}=$ acute myocardial infarction, $\mathrm{TVR}=$ target vessel revascularisation.

\section{DISCUSSION}

In this prospective, multicentre, international registry, the non-polymeric paclitaxel-eluting Amazonia PAX ${ }^{\circledR}$ stent showed excellent immediate results (device/angiographic success of $100 \%$ and procedural success of $96.1 \%$ ), as well as sustained safety after one year. However, its clinical effectiveness was lower than that reported for other DES, with and without polymers. ${ }^{1-3,7-11,24-28}$ Notably, the angiographic findings in the long-term follow-up of the PAX-B study are similar to results reported with other previously tested non-polymeric paclitaxel-releasing stents, ${ }^{6}$ which also confirms that the Amazonia PAX ${ }^{\circledR}$ stent is less effective than the Taxus ${ }^{\circledR}$ Liberté paclitaxel-releasing stent with durable polymer at suppressing neointimal proliferation. ${ }^{19}$

In general, first-generation DES, such as Cypher ${ }^{\circledR}$ (Cordis - Miami Lakes, USA) and Taxus ${ }^{\circledR}$, demonstrated remarkable and sustained clinical effectiveness. ${ }^{29}$ However, the durable polymeric components used as drug carriers in these devices were shown to cause an intense local inflammatory response, ${ }^{30,31}$ which has been associated with recurrence and late thrombotic phenomena. ${ }^{15,16,32,33}$ Thus, the second generation of DES introduced more biocompatible polymers and systems with biodegradable polymers. . $^{7,10,11}$ Recent studies suggest that these devices have an improved safety profile compared to the first generation of DES, without compromising their clinical effectiveness. ${ }^{34,35}$ Nonetheless, the development of DES without polymers (third-generation DES) could, at least in theory, offer additional advantages, such as a) the prevention of adverse effects due to the prolonged or temporary presence of polymeric residues; b) the optimisation of vascular healing; c) the sustained integrity of the stent surface; and d) the maintenance of dual antiplatelet therapy for shorter periods. ${ }^{36}$ However, the removal of the polymer from the DES may overly compromise its effectiveness, as the polymer is responsible not only for carrying the drug, but also for controlling release kinetics. ${ }^{6}$ Previous studies have shown that using a non-polymeric stent coating is safe and may lead to a dose-dependent decrease in restenosis rates; however, these studies have also demonstrated that the critical aspect is the elution profile of the antiproliferative drug. ${ }^{6,17,18}$ In the current analysis, the relatively small sample size ( $\mathrm{n}=103$ ) notwithstanding, impairment in safety was not observed, despite the high prevalence of complex cases and lesions, including an absence of death or stent thrombosis up to the 12-month follow-up. However, the unexpectedly high rates of recurrence indicate the technological challenge of maintaining effectiveness in the absence of a polymer.

In the prospective, randomised, multicentre study DELIVER, which included 1,043 patients, the nonpolymeric, paclitaxel-releasing DES Achieve ${ }^{\circledR}$ (Guidant Corp. - Santa Clara, CA, USA) presented a mean late in-stent lumen loss of $0.81 \pm 0.60 \mathrm{~mm}$ at the eightmonth follow-up (vs. $0.98 \pm 0.57 \mathrm{~mm}$ in the control group, treated with BMS, $\mathrm{P}=0.003$ ); however, this difference did not translate into significant decreases in the rates of binary restenosis or TLR. In this case, the device in the active group (Achieve ${ }^{\circledR}$ stent) received a coating of paclitaxel at a dose of $3 \mu \mathrm{g} / \mathrm{mm}^{2}$ of the stent surface area. ${ }^{6}$ Similar to the first generation Taxus ${ }^{\circledR}$ Liberté DES, which incorporates a durable polymer, the paclitaxel dose is rather low $\left(1 \mu \mathrm{g} / \mathrm{mm}^{2}\right.$ of the stent surface area). ${ }^{3}$ Nevertheless, preclinical studies have estimated a significant loss of the antiproliferative agent (up to $40 \%$ of the total) during stent delivery with the nonpolymeric device when compared to $<10 \%$ of drug elution in 30 days with the Taxus ${ }^{\circledR}$ stent. ${ }^{3,6}$ With the Amazonia PAX ${ }^{\circledR}$ stent, tested in the PAX-A and PAX-B studies, the medians of late in-stent lumen loss were 0.77 [0.47; 1.05$] \mathrm{mm}$ (four months) and $0.91[0.50 ; 1.21] \mathrm{mm}$ (nine months), respectively. It is noteworthy that the paclitaxel dose (or concentration) was $0.67 \mu \mathrm{g} / \mathrm{cm}^{2}$ of the stent surface area, 
with $33 \%-52 \%$ of the drug being released within eight hours; $55 \%-75 \%$, within a week; and $100 \%$, in 45 days. ${ }^{19}$ Thus, the kinetics of drug release appear to explain, at least in part, the greater efficacy observed with polymeric vs. non-polymeric DES, despite the use of the same drug (in this case, paclitaxel) and a reduced dose. ${ }^{6,19}$ Greater efficacy has also been observed with stents releasing drugs from the 'limus' class. ${ }^{1,2,7,11,24,25}$ Late angiographic results with the non-polymeric sirolimus-releasing DES Yukon ${ }^{\circledR}$ (Translumina $\mathrm{GmbH}$, Hechingen, Germany) demonstrated relatively lower efficacy when compared with results of the first generation sirolimus-releasing DES Cypher $^{\circledR}$. In the prospective, randomised study, Intracoronary Stenting and Angiographic Restenosis (ISAR-TEST), which included 450 patients, the mean late in-stent lumen loss was $0.48 \pm 0.61 \mathrm{~mm}$ with the Yukon ${ }^{\circledR}$ stent (vs. $0.48 \pm 0.58 \mathrm{~mm}$ with the Taxus ${ }^{\circledR}$ stent). ${ }^{24}$ Similarly, in the ISAR-TEST 3, which compared three sirolimuseluting stents, including non-polymeric, biodegradable polymer and durable polymer systems $\left(\right.$ Cypher $\left.^{\circledR}\right)$, the late in-stent lumen loss was $0.47 \pm 0.56 \mathrm{~mm}$ vs. $0.17 \pm 0.45 \mathrm{~mm}$ vs. $0.23 \pm 0.46 \mathrm{~mm}$, respectively. ${ }^{37}$

Alternatives tested in non-polymeric DES have included the incorporation of nonpolymeric carrier components and the structural modification of metal surfaces. The VESTAsync system (MIV Therapeutics, Atlanta, GA, USA) has a microporous hydroxyapatite coating that carries the drug sirolimus at a reduced dose (approximately $40 \%$ of the dose used in the Cypher ${ }^{\circledR}$ stent). In the initial study in humans $(n=15)$, the late in-stent lumen loss was $0.30 \pm 0.25 \mathrm{~mm}$ at four months and $0.36 \pm 0.23 \mathrm{~mm}$ at nine months. Correspondingly, the obstruction volume percentage with intracoronary ultrasound was $2.8 \pm 2.2 \%$ at four months and $4 \pm 2.2 \%$ at nine months. It is important to highlight that the VESTAsync stent had a drug-elution profile similar to that of the Cypher ${ }^{\circledR}$ stent, with total release attained at 90 days. ${ }^{25,28}$ Additionally, the results of a new nonpolymeric system using active carrier substances released from a 'bioinductor' surface (Cre8, CID - Saluggia, Italy) have been recently reported. In this prospective randomised study $(\mathrm{n}=323)$, the nonpolymeric stent Cre8, which releases a 'limus' drug, showed a late in-stent lumen loss at six months of $0.14 \pm 0.36 \mathrm{~mm}$ vs. $0.34 \pm 0.40 \mathrm{~mm}$ for the Taxus ${ }^{\circledR}$ Liberté stent $(P<0.0001) .{ }^{26}$ Finally, the BioFreedom ${ }^{\circledR}$ stent (Biosensors International - Singapore) incorporates a technology that uses a modified abluminal metal surface and does not use a polymer, resulting in a microporous structure that allows adhesion and the release of the antiproliferative agent Biolimus $A 9$. In the prospective, randomised, BIOFREEDOM study, 182 patients were randomised into three groups and divided into two cohorts according to an angiographic restudy at four months $(n=75)$ or 12 months $(n=107)$. At four months, the median values of late in-stent lumen loss was 0.08 [0.02;0.14] mm, 0.12 [0.07; 0.25] mm vs. $0.37[0.14 ; 0.50] \mathrm{mm}$ for the BioFreedom standard dose, the BioFreedom reduced dose, and the Taxus ${ }^{\circledR}$ Liberté, respectively; at 12 months, the values were $0.17[0.09 ; 0.39] \mathrm{mm}, 0.22[0.17 ; 0.66] \mathrm{mm}$ vs. 0.35 $[0.22 ; 0.57] \mathrm{mm}$, respectively $(\mathrm{P}=0.001$ for noninferiority in the comparison of the standard dose BioFreedom group vs. Taxus $\left.{ }^{\circledR}\right) .{ }^{27}$ Notably, both the Cre8 and the BioFreedom stents showed efficacy that was relatively superior to that of other reported nonpolymeric DES. ${ }^{26,27}$ Possible reasons for the improved efficacy include the use of the 'limus' drug family, which has demonstrated superiority in inhibiting neointimal hyperplasia in relation to other classes of drugs, including paclitaxel. ${ }^{38}$ Moreover, the Cre8 system has drug release kinetics that are similar to the first- and second-generations polymeric DES. ${ }^{26}$ In contrast, approximately $90 \%$ of the drug is released within 48 hours after BioFreedom implantation; ${ }^{27}$ however, the drug release kinetics do not appear to have an impact on efficacy, as observed in other systems. It is speculated that this effect is probably due to the high lipophilicity of the drug Biolimus A9 (ten times greater than that of sirolimus), thus ensuring optimal drug absorption and a longer-lasting antiproliferative effect. In the case of the Amazonia PAX ${ }^{\circledR}$ stent tested in the present study, a new model, which utilizes a new carrier and release technology for the drug sirolimus based on nanoparticle encapsulation technology ('LEX'), has been developed (preclinical studies are in progress). This new model should increase the effectiveness in inhibiting neointimal hyperplasia for that system (R. Costa, personal communication, TCT 2011. San Francisco, CA, USA).

\section{CONCLUSIONS}

In this prospective, multicentre, international registry, the new drug-eluting, non-polymeric paclitaxel-releasing Amazonia ${ }^{\circledR}$ PAX stent showed excellent immediate results and a high safety profile, including the absence of death or stent thrombosis after one year of follow-up. However, recurrence rates were relatively high because of the low effectiveness of neointimal hyperplasia inhibition.

\section{CONFLICTS OF INTEREST}

The authors declare no conflicts of interest. 


\section{REFERENCES}

1. Sousa JE, Costa MA, Abizaid A, Abizaid AS, Feres F, Pinto IM, et al. Lack of neointimal proliferation after implantation of sirolimus-coated stents in human coronary arteries: a quantitative coronary angiography and three-dimensional intravascular ultrasound study. Circulation. 2001;103(2):192-5.

2. Moses JW, Leon MB, Popma JJ, Fitzgerald PJ, Holmes DR, O'Shaughnessy C, et al. Sirolimus-eluting stents versus standard stents in patients with stenosis in a native coronary artery. $\mathrm{N}$ Engl J Med. 2003;349(14):1315-23.

3. Stone GW, Ellis SG, Cox DA, Hermiller J, O'Shaughnessy C, Mann JT, et al. A polymer-based, paclitaxel-eluting stent in patients with coronary artery disease. N Engl J Med. 2004; 350(3):221-31

4. Kirtane AJ, Gupta A, Iyengar S, Moses JW, Leon MB, Applegate R, et al. Safety and efficacy of drug-eluting and bare metal stents: comprehensive meta-analysis of randomized trials and observational studies. Circulation. 2009;119(25):3198-206.

5. Daemen J, Wenaweser P, Tsuchida K, Abrecht L, Vaina S, Morger C, et al. Early and late coronary stent thrombosis of sirolimus-eluting and paclitaxel-eluting stents in routine clinical practice: data from a large two-institutional cohort study. Lancet. 2007;369(9562):667-78.

6. Lansky AJ, Costa RA, Mintz GS, Tsuchiya Y, Midei M, Cox DA, et al. Non-polymer-based paclitaxel-coated coronary stents for the treatment of patients with de novo coronary lesions: angiographic follow-up of the DELIVER clinical trial. Circulation. 2004;109(16):1948-54.

7. Meredith IT, Ormiston J, Whitbourn R, Kay IP, Muller D, Bonan R, et al. First-in-human study of the endeavor ABT-578-eluting phosphorylcoline-encapsulated stent system in de novo native coronary artery lesions: ENDEAVOR I Trial. Eurolntervention. 2005;1(2):157-64.

8. Serruys PW, Ong AT, Piek JJ, Neumann FJ, van der Giessen WJ, Wiemer $\mathrm{M}$, et al. A randomized comparison of a durable polymer Everolimus-eluting stent with a bare metal coronary stent: the SPIRIT first trial. Eurolntervention. 2005;1(1):58-65.

9. Costa RA, Lansky AJ, Mintz GS, Mehran R, Tsuchiya Y, Negoita M, et al. Angiographic results of the first human experience with everolimus-eluting stents for the treatment of coronary lesions (the Future I trial). Am J Cardiol. 2005;95(1):113-6.

10. Costa RA, Lansky AJ, Abizaid A, Mueller R, Tsuchiya Y, Mori K, et al. Angiographic results of the first human experience with the Biolimus A9 drug-eluting stent for de novo coronary lesions. Am J Cardiol. 2006;98(4):443-6.

11. Meredith IT, Worthley S, Whitbourn R, Walters D, Popma J, Cutlip $\mathrm{D}$, et al. The next-generation endeavor resolute stent: 4-month clinical and angiographic results from the endeavor resolute first-in-man trial. Eurolntervention. 2007;3(1):50-3.

12. lakovou I, Schmidt T, Bonizzoni E, Ge L, Sangiorgi GM, Stankovic G, et al. Incidence, predictors, and outcome of thrombosis after successful implantation of drug-eluting stents. JAMA. 2005;293(17):2126-30.

13. Costa RA, Sousa AGMR, Moreira AC, Costa JR Jr, Maldona-do G, Cano M, et al. Trombose de stent farmacológico no "mundo-real": análise crítica do Registro DESIRE (Drug-Elu ting Stent in the Real World). Rev Bras Cardiol Invasiva. 2008; 16(2):144-54.

14. Joner M, Finn AV, Farb A, Mont EK, Kolodgie FD, Ladich E, et al. Pathology of drug-eluting stents in humans: delayed healing and late thrombotic risk. J Am Coll Cardiol. 2006;48(1):193-202.

15. Finn AV, Nakazawa G, Joner M, Kolodgie FD, Mont EK, Gold HK, et al. Vascular responses to drug eluting stents: Importance of delayed healing. Arterioscler Thromb Vasc Biol. 2007;27(7):1500-10.
16. Virmani R, Guagliumi G, Farb A, Musumeci G, Grieco N Motta $\mathrm{T}$, et al. Localized hypersensitivity and late coronary thrombosis secondary to a sirolimus-eluting stent: should we be cautious? Circulation. 2004;109(6):701-5.

17. Park SJ, Shim WH, Ho DS, Raizner AE, Park SW, Hong MK, et al. A paclitaxel-eluting stent for the prevention of coronary restenosis. N Engl J Med. 2003;348(16):1537-45.

18. Gershlick A, De Scheerder I, Chevalier B, Stephens-Lloyd A, Camenzind $E$, Vrints $C$, et al. Inhibition of restenosis with a paclitaxel-eluting, polymer-free coronary stent: the European evaluation of pacliTaxel Eluting Stent (ELUTES) trial. Circulation. 2004;109(4):487-93.

19. Chamié D, Costa JR Jr, Abizaid A, Costa RA, Feres F, Staico R, et al. Comparação randomizada entre o stent eluidor de paclitaxel de nova geração sem polímero e o stent eluidor de paclitaxel com polímero durável em pacientes com doença arterial coronária: resultados da análise angiográfica e ultrassonográfica seriada do Estudo PAX-A. Rev Bras Cardio Invasiva. 2011;19(4):379-91.

20. King SB 3rd, Smith SC Jr, Hirshfeld JW Jr, Jacobs AK, Morrison DA, Williams DO, et al. 2007 Focused Update of the ACC/AHA/SCAI 2005 Guideline Update for Percutaneous Coronary Intervention: a report of the American College of Cardiology/American Heart Association Task Force on Practice Guidelines: 2007 Writing Group to Review new Evidence and Update the ACC/AHA/SCAI 2005 Guideline Update for Percutaneous Coronary Intervention, Writing on Behalf of the 2005 Writing Committee. Circulation. 2008;117(2):261-95.

21. Cutlip DE, Windecker S, Mehran R, Boam A, Cohen DJ, van Es GA, et al. Clinical end points in coronary stent trials: a case for standardized definitions. Circulation. 2007;115(17):2344-51.

22. Popma JJ, Gibson CM. Qualitative and quantitative angiography. In: Topol EJ, ed. Textbook of interventional cardiology. Philadelphia: Saunders; 2003.

23. Mehran R, Dangas G, Abizaid AS, Mintz GS, Lansky AJ, Satler LF, et al. Angiographic patterns of in-stent restenosis: classification and implications for long-term outcome. Circulation. 1999;100(18):1872-8.

24. Mehilli J, Kastrati A, Wessely R, Dibra A, Hausleiter J, Jaschke B, et al. Randomized trial of a nonpolymer-based rapamycinelu ting stent versus a polymer-based paclitaxel-eluting stent for the reduction of late lumen loss. Circulation. 2006; 113(2):273-9.

25. Costa JR Jr, Abizaid A, Costa R, Feres F, Tanajura LF, Maldo-nado G, et al. 1-year results of the hydroxyapatite polymer-free sirolimus-eluting stent for the treatment of single de novo coronary lesions: the VESTASYNC I trial. JACC Cardiovasc Interv. 2009;2(5):422-7.

26. Carriè D, Berland J, Verheye S, Hauptmann KE, Vrolix M, Violini $\mathrm{R}$, et al. A multicenter randomized trial comparing amphilimus- with paclitaxel-eluting stents in de novo native coronary artery lesions. J Am Coll Cardiol. 2012; 59(15):1371-6.

27. Costa RA, Abizaid A, Mehran R, Magalhaes MA, Gambone L, Parise $\mathrm{H}$, et al. De novo coronary lesions treated with the novel polymer-free biolimus-a9 coated stents: 12-month angiographic results from the prospective, randomized, multicenter biofreedom clinical trial. J Am Coll Cardiol. 2011;57:E1645.

28. Costa JR Jr, Abizaid A, Costa R, Feres F, Tanajura LF, Mattos LA, et al. Preliminary results of the hydroxyapatite nonpolymerbased sirolimus-eluting stent for the treatment of single de novo coronary lesions a first-in-human analysis of a thirdgeneration drug-eluting stent system. JACC Cardiovasc Interv. 2008;1(5):545-51 
29. Stone GW, Moses JW, Ellis SG, Schofer J, Dawkins KD, Morice MC, et al. Safety and efficacy of sirolimus-and paclitaxel-eluting coronary stents. N Engl J Med. 2007;356(10):998-1008.

30. van der Giessen WJ, Lincoff AM, Schwartz RS, van Beusekom HM, Serruys PW, Holmes DR Jr, et al. Marked inflammatory sequelae to implantation of biodegradable and nonbiodegradable polymers in porcine coronary arteries. Circulation. 1996; 94(7):1690-7.

31. Suzuki T, Kopia G, Hayashi S, Bailey LR, Llanos G, Wilensky R, et al. Stent-based delivery of sirolimus reduces neointimal formation in a porcine coronary model. Circulation. 2001; 104(10):1188-93.

32. Cook S, Ladich E, Nakazawa G, Eshtehardi P, Neidhart M, Vogel $R$, et al. Correlation of intravascular ultrasound findings with histopathological analysis of thrombus aspirates in patients with very late drug-eluting stent thrombosis. Circulation. 2009;120(5):391-9.

33. Cook S, Wenaweser P, Togni M, Billinger M, Morger C, Sei-ler C, et al. Incomplete stent apposition and very late stent thrombosis after drug-eluting stent implantation. Circulation. 2007:115(18):2426-34.
34. Stefanini GG, Kalesan B, Serruys PW, Heg D, Buszman P, Linke $A$, et al. Long-term clinical outcomes of biodegradable polymer biolimus-eluting stents versus durable polymer sirolimus-eluting stents in patients with coronary artery disease (LEADERS): 4 year follow-up of a randomised non-inferiority trial. Lancet. 2011;378(9807):1940-8.

35. Bangalore S, Kumar S, Fusaro M, Amoroso N, Attubato MJ Feit $F$, et al. Short- and long-term outcomes with drug-eluting and bare-metal coronary stents: a mixed-treatment comparison analysis of 117762 patient-years of follow-up from randomized trials. Circulation. 2012;125(23):2873-91.

36. Abizaid A, Costa JR Jr. New drug-eluting stents: an overview on biodegradable and polymer-free next-generation stent systems. Circ Cardiovasc Interv. 2010;3(4):384-93.

37. Mehilli J, Byrne RA, Wieczorek A, lijima R, Schulz S, Bruskina O, et al. Randomized trial of three rapamycin-eluting stents with different coating strategies for the reduction of coronary restenosis. Eur Heart J. 2008;29(16):1975-82.

38. Morice MC, Colombo A, Meier B, Serruys P, Tamburino C, Guagliumi G, et al. Sirolimus- vs paclitaxel-eluting stents in de novo coronary artery lesions: the REALITY trial: a randomized controlled trial. JAMA. 2006;295(8):895-904. 